\title{
CPS Based Liquid Metal Divertor Target for EU-DEMO
}

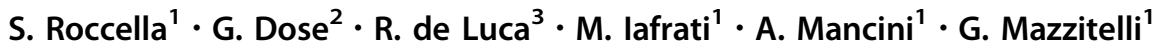

Received: 3 June 2020/Revised: 29 September 2020 / Accepted: 3 October 2020 / Published online: 24 October 2020

(C) The Author(s) 2020

\begin{abstract}
Power exhaust is a key mission in the roadmap to the realization of a future fusion reactor. Among the different solutions, the use of liquid metals as plasma facing materials are of interest due to their potential increased lifetime. Several liquid metal limiters have been successfully tested in the Frascati Tokamak Upgrade over the last 10 years. Liquid materials such as lithium and tin have been investigated using capillary porous systems (CPSs), and their impact on plasma performance has been explored. From such experience, a liquid metal divertor (LMD) concept design, CPS-based, is here proposed. Tin has been preferred as plasma facing material. The proposed LMD would operate, in low evaporative regime, with matching heat exhausting capabilities to those of the baseline ITER-like divertor. Continuous refilling of the CPS is guaranteed with a reservoir at the back of the unit, where the metal is kept liquid through a gas heating circuit. The study has been carried out using ANSYS and the thermal results will be shown. All the design choices are compatible with the current materials and the constraints adopted for the DEMO W divertor. Using such configuration, thermal loads up to $20 \mathrm{MW} / \mathrm{m}^{2}$ are exhausted while keeping the surface temperature below $1250{ }^{\circ} \mathrm{C}$. The design foresees values of pressure, temperature and flow rate of the water coolant in the same range expected for the W DEMO divertor, thus facilitating the integration of such solution in the current cassette design. Technological and practical aspects are addressed, i.e. tin corrosion and CPS wettability. Possible solutions to prevent tin corrosion, and its compatibility with structural materials, will be outlined.
\end{abstract}

Keywords DEMO $\cdot$ Liquid metal divertor $\cdot$ Plasma facing component $\cdot$ Tin

\section{Introduction}

The baseline strategy for the DEMO divertor plasma facing units (PFUs) consists in the $\mathrm{W}$ monoblock design, which foresees $\mathrm{CuCrZr}$ heat sink pipes joined to $\mathrm{W}$ monoblock armor through a soft $\mathrm{Cu}$ interlayer [1]. Lifetime of such components is affected by erosion, thermal fatigue, as well as damage due to a significant neutron flux. Many experiments [2] have confirmed liquid metals (LMs) as a promising candidate for plasma facing material. Their peculiar advantages are:

S. Roccella

selanna.roccella@enea.it

1 Department of Fusion and Technology for Nuclear Safety and Security, ENEA, Frascati, Italy

2 Industrial Engineering Department, University di Rome "Tor Vergata", Via del Politecnico 1, 00133 Rome, Italy

3 DEIm Department, University of Tuscia, Via del Paradiso 47, 01100 Viterbo, Italy
1. Self-healing/renewability of the plasma facing surface.

2. Less sensitivity to the neutron damage.

As a result, an increased lifetime with respect to a solid wall is expected. Possible liquid metal choices include lithium ( $\mathrm{Li}$ ) and tin $(\mathrm{Sn}) . \mathrm{Li}$ is a low $\mathrm{Z}$ material $(\mathrm{Z}=3)$, which allows for good plasma performance. However, the Li operational window is rather narrow, and must operate below $680{ }^{\circ} \mathrm{C}$ [3] to avoid strong evaporation. On the other hand, $\mathrm{Sn}$ is a high $\mathrm{Z}$ element $(\mathrm{Z}=50)$, which can lead to radiation losses not only in the outer plasma regions. However, Sn benefits from a larger operational window since low evaporation is observed up to $1250{ }^{\circ} \mathrm{C}$ [3]. In addition, it provides low or negligible activation and less safety issues in combination with water cooling.

Regarding the $\mathrm{H}$ retention of the liquid $\mathrm{Sn}$, the results that can be found in literature are rather discordant: very low retention was found in [4], while higher values are reported in [5] and [6]. In any case, even the most pessimistic results are not such as to discourage the use of Sn. 
Extensive experience gained at the Frascati Tokamak Upgrade (FTU) using both $\mathrm{Li}$ and $\mathrm{Sn}$ targets suggests that the behavior of such components could be compatible with quasi-stationary operation [7]. In fact, FTU campaigns suggested that Sn contamination would not affect the typically metallic machine behavior. The plasma performances appeared unaffected and compatible with the usual scenario with a molybdenum limiter [7].

In this study, we present a Sn-based conceptual design of an actively cooled LM PFU developed in ENEA. Design requirements were chosen according to the specifications of the DEMO divertor targets [1]. In the present analysis, no power is lost due to phase change, as Sn operates below the temperature limit $\left(1250{ }^{\circ} \mathrm{C}\right)$ for high evaporation. CPS has been chosen as LM containment structure. Rather than having a flowing LM, the design choice is to keep the LM basically still; the only motion is the refilling of the evaporated material due to capillary forces. The porous structure confines the LM and hinders the potential MHD melt motion owing to electromagnetic loads that arise during transients. In this work, the thermal behavior under DEMO relevant conditions of the proposed design is presented.

\section{Conceptual Design}

\section{Geometry and Materials}

A schematic cross-section of the LMD target is reported in Fig. 1. The design comprises: the CPS, a heat sink

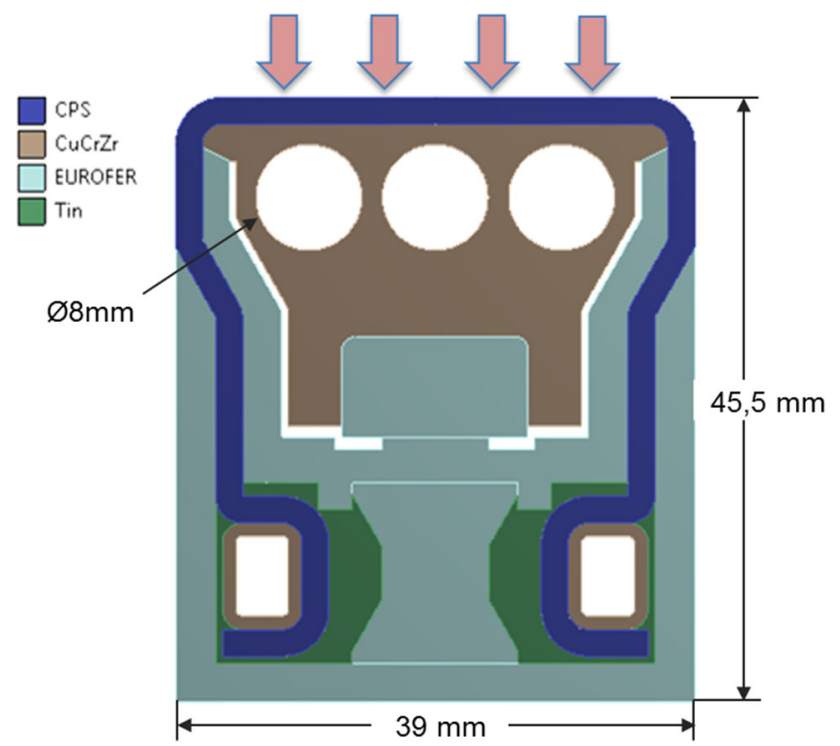

Fig. 1 Schematic 2D design of the LMD module. The arrows indicate the plasma facing surface dedicated to exhausting the heat coming from the plasma and a reservoir designed to supply the LM.

The CPS consists of a porous structure (typically W based mesh or felt) that exploits capillary forces to provide an effective refill, as well as to confine the LM at the plasma facing surface. In our design it has a thickness of $2 \mathrm{~mm}$, being this value in the range of the one used in the experimental experiences on FTU. The CPS soaked by liquid Sn plays the role of the armor material. Unlike solid armors, in a LM target small thicknesses can indeed be achieved since the refilling times are small enough to ensure the replenishment of LM and the self-healing of the plasma facing surface. Wetting tests on W-based meshes and felts have revealed that this feature is mainly influenced by the size and effective radius of the chosen structure [8]. Due to the Sn corrosion, a thin W coating in the order of few hundred microns is mandatory to protect all the surfaces in contact with the LM. The limited literature on the topic suggests good compatibility between $\mathrm{W}$ and $\mathrm{Sn}[9-11]$.

Nonetheless, corrosion analyses are ongoing for the expected operating conditions. In the present calculation, the coating layer was not modelled owing to its negligible thermal resistance resulting from the small thickness.

The geometry in Fig. 1, used for the present analysis, represents the cross section of the 3D component already designed and of which some mock-ups are under fabrication. The description of the thermo-mechanical behavior of the 3D component and the mock-up fabrication will be subject of a future publication.

The 3D component is composed of a central structure made of Eurofer, machined from a single block. This central steel structure is attached from one side to the heat sink and to the other to the reservoir.

The heat sink body consists in a single-block with three circular cooling channels having a diameter of $8 \mathrm{~mm}$. Two alternatives have been considered as the heat sink material: $\mathrm{CuCrZr}$ and a composite $\mathrm{W} / \mathrm{Cu}$. The former has been chosen since it is the reference heat sink material for divertor targets. On the other hand, copper alloys might not be relevant for a DEMO reactor, where a significant neutron flux may lead to material activation and excessive degradation of its properties. Therefore, W/Cu composite having $70 \% \mathrm{wt}$. of $\mathrm{W}$ content was investigated as an alternative option. Its material properties were taken from existing literature $[12,13]$. The $\mathrm{W}$ concentration in the composite can be changed based on inputs from neutronic analyses which will be carried out in a second phase.

The heat sink is fixed to the steel structure with pins inserted in horizontal slot machined in the central rib of the structure. This solution allows sliding between the two parts due to their different thermal expansion coefficients, reducing the thermal stresses in the component. In the 
thermal FEM calculation, reported here, the thermal contact resistance between Eurofer and heat sink has been neglected by assuming perfectly bonded surfaces. This leads to conservative results, since the heat transfer between the heat sink and the hot reservoir is overestimated.

After fixing the heat sink to the structure, the CPS can be placed around the component. The steel box, which houses the gas heating circuit is mounted last, and has the task of both containing the LM and also anchoring the CPS. The reservoir is fixed to the steel structure by means of screw joints placed in the bottom part. Even if this solution might not be employable in a fusion reactor for safety reasons, it was chosen for the mock-ups to allow easy refilling of the reservoir and replacement of the CPS. Towards the final design, screw joints could be easily replaced by welding.

In the proposed layout, heat transfer between heat sink and the reservoir is hindered due to the presence of a gap which impedes heat conduction. In such a way, we have an effective decoupling between a water-cooled part of the component which has the sole purpose of exhausting heat form the plasma, and a gas-heated reservoir devoted to refilling.

For the simulations, the adopted Sn properties are listed in Table 1. Phase change of Sn has been taken into account by means of a change in the material properties, from solid to liquid, at the melting temperature $\left(232{ }^{\circ} \mathrm{C}\right)$. Melting kinetics was not implemented, since all calculation has been carried out in steady-state. The equivalent thermophysical properties of the CPS have been calculated by a linear mixture law, assuming a Sn volume fraction of $50 \%$ vol. with respect to $\mathrm{W}$. Properties of $\mathrm{W}$ and $\mathrm{CuCrZr}$ were taken from the ITER SDC-IC [14], while for Eurofer we adopted [15]. In this paper, porosity of the CPS will not be addressed in detail, even if it has a substantial impact on the performances of the CPS. However, the thermal design is not affected by the choice of pore size, having modeled the CPS material as a homogenized body. In fact, the CPS can theoretically have any porosity at fixed Sn-volume fraction and CPS total volume, which are the only relevant parameters for the thermal analysis; especially in our case

Table 1 Pure Sn material properties

\begin{tabular}{llll}
\hline $\begin{array}{l}\text { Temperature } \\
\left({ }^{\circ} \mathrm{C}\right)\end{array}$ & $\begin{array}{l}\text { Density } \\
\left(\mathrm{kg} / \mathrm{m}^{3}\right)\end{array}$ & $\begin{array}{l}\text { Thermal conductivity } \\
(\mathrm{W} / \mathrm{mK})\end{array}$ & $\begin{array}{l}\text { Specific heat } \\
(\mathrm{J} / \mathrm{kgK})\end{array}$ \\
\hline 20 & 7290 & 63.2 & 256 \\
200 & 7290 & 56.5 & 256 \\
232 & 6450 & 32.6 & 213 \\
332 & 5770 & 32.6 & 213 \\
\hline
\end{tabular}

where the pore diameter is far smaller than the CPS thickness (tens of microns vs. millimeters).

\section{Design requirements}

The thermal design was conducted in order to respect the following boundaries:

1. Surface temperature must not exceed 1250 ? to avoid high Sn evaporation. (No vapor shielding effects are therefore implemented in the thermal model).

2. Nominal steady-state load absorbed by the component is fixed to a maximum value of $20 \mathrm{MW} / \mathrm{m}^{2}$.

3. Sn on the plasma facing surface must remain liquid, even at the minimum expected power density on the divertor, assumed equal to $5 \mathrm{MW} / \mathrm{m}^{2}$ [16].

4. The Critical Heat Flux (CHF) margin must be higher than 1.4, as also adopted in ITER [17].

5. Operative temperatures ranges inside the materials under neutron irradiation must respect the following requirements: $\sim 150-350{ }^{\circ} \mathrm{C}$ for $\mathrm{CuCrZr}$ and $300-550{ }^{\circ} \mathrm{C}$ for Eurofer $[1,18,19]$. For $\mathrm{W} / \mathrm{Cu}$ composites no existing data is available regarding neutron embrittlement.

6. Quantities of high/moderate activation materials must be reduced to the minimum possible. Although low activation is desired, at present the need for a viable solution for the divertor overwhelms this [19].

\section{Design Choices}

In order to match the steel operational window, the gas temperature cannot be lower than $300{ }^{\circ} \mathrm{C}$. In the present analysis, this parameter was fixed to $350{ }^{\circ} \mathrm{C}$ to meet requirement 3 .

The thermo-hydraulic conditions are listed in Table 2 and compared to those of the solid DEMO divertor [1]. For the case of $\mathrm{CuCrZr}$, the operational temperature was raised to $140{ }^{\circ} \mathrm{C}$ with respect to the DEMO baseline, in order to verify requirement 3 and at the same time better satisfying requirement 5 . For the $\mathrm{W} / \mathrm{Cu}$ concept, due to the lack of knowledge in the scientific community of operational constraints, the same temperature as the reference was kept. A water velocity of $12 \mathrm{~m} / \mathrm{s}$ was selected because higher velocities showed phenomena of "erosion/corrosion" at the pipe inner surface [20]. Water pressure was set at $5 \mathrm{MPa}$, as in the DEMO design.

Having given these parameters, the heat transfer coefficient (HTC) can be calculated from the following semiempirical laws [21]: Sieder-Tate for single-phase convection, Thom-CEA correlations for nucleate boiling regimes 
Table 2 Water cooling parameters

\begin{tabular}{llll}
\hline & DEMO monoblock & CuCrZr heat sink & W/Cu heat sink \\
\hline Pressure $(\mathrm{MPa})$ & 5 & 5 & 5 \\
Temperature $\left({ }^{\circ} \mathrm{C}\right)$ & 130 & 140 & 130 \\
Tape Twist Ratio & 2 & 2 & 2 \\
Velocity $(\mathrm{m} / \mathrm{s})$ & 12 & 12 & 12 \\
Pressure drop $(\mathrm{bar} / \mathrm{m})$ & 3.5 & 6.0 & 6.0 \\
Critical heat flux $\left(\mathrm{MW} / \mathrm{m}^{2}\right)$ & 42.3 & 40.4 & 43.2 \\
Peaking factor & 1.75 & 1.38 & 1.42 \\
CHF Margin $\left(\mathrm{ICHF} / 20 \mathrm{MW} / \mathrm{m}^{2}\right)$ & 1.21 & 1.46 & 1.52 \\
\hline
\end{tabular}

and Bergles-Rohsenow for the onset of nucleate boiling. The resulting HTC is a function of the temperature at the pipe wall, Fig. 2

An additional key parameter related to the heat exhaust capabilities of water cooled PFU is the Critical Heat Flux $(\mathrm{CHF})$, i.e. the maximum heat flux that can be absorbed at the pipe by cooling water before reaching the boiling crisis. At such a point, bubble coalescence forms a vapor film that insulates the pipe wall from the water, leading to an abrupt failure. The $\mathrm{CHF}$ is not evaluated at the plasma facing surface, but at the pipe at the CHF event. The corresponding heat flux flowing through the plasma facing surface differs from the CHF due to a flux concentration which depends on the component geometry and the material properties. To take into account such concentration, it is common practice to define the peaking factor, $\mathrm{f}_{\mathrm{p}}$. Consequently, one gets the corresponding heat flux flowing through the plasma facing surface, namely the Incident Critical Heat Flux (ICHF), by dividing the CHF by the peaking factor $\left(\mathrm{ICHF}=\mathrm{CHF} / \mathrm{f}_{\mathrm{p}}\right)$.

The ICHF divided by the design heat flux $q_{0}(20 \mathrm{MW} /$ $\mathrm{m}^{2}$ ) defines the CHF margin. This margin is 1.4 for the ITER divertor design [17]. The CHF is strongly dependent on the bulk water temperature: higher temperatures lead to a drop in CHF by decreasing the difference between bulk and saturation temperatures. To compensate the reduction

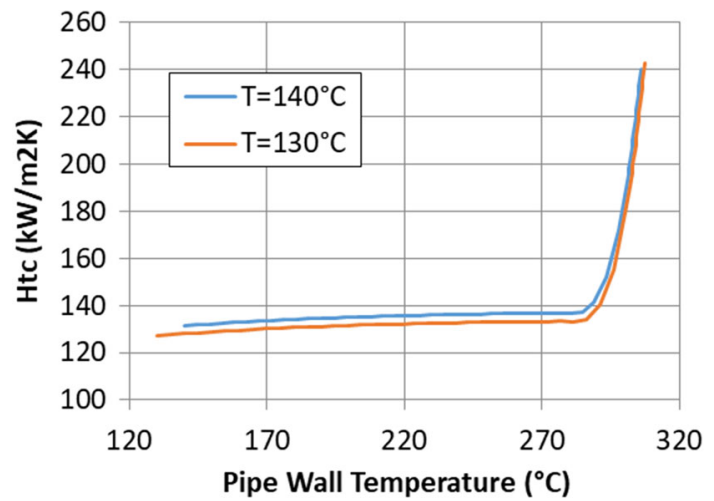

Fig. $2 \mathrm{HTC}$ as a function of the pipe wall temperature (see water parameters in Table 2) in $\mathrm{CHF}$ margin, an increase in water pressure would be required. However, approaching the critical pressure, the water latent heat of vaporization goes to zero. Therefore, bubble formation is facilitated and a further increase in water pressure does not result in an additional increase in CHF. This physical behavior is qualitatively caught by the modified Tong-75 empirical correlation [22], used for the ITER divertor design and plotted in Fig. 3.

To keep the Tin liquid with the same water used for the heat exhaust, a bulk temperature of around $250{ }^{\circ} \mathrm{C}$ is needed. On the base of the modified Tong-75 correlation (at $250{ }^{\circ} \mathrm{C}$ and with a reasonable velocity of $12 \mathrm{~m} / \mathrm{s}$ ) the maximum $\mathrm{CHF}$ of $26.6 \mathrm{MW} / \mathrm{m}^{2}$ occurs at 153.7 bar. Even by finding an optimal design with a very low peaking factor, the $\mathrm{CHF}$ margin remains small with dangerous risk of component failure. For instance, by assuming an optimistic peaking factor of 1.20 , an ICHF of $21.3 \mathrm{MW} / \mathrm{m}^{2}$ is derived, with a CHF margin of 1.1. Based on these considerations, it was chosen in our design to adopt two separated circuits: the first for heat removal and the second for keeping Sn liquid. This represents an advantage not only in terms of $\mathrm{CHF}$ margin, but also in respect to maintaining lower pressures in the water circuit, which results in a more agile integration of this design into the actual DEMO divertor.

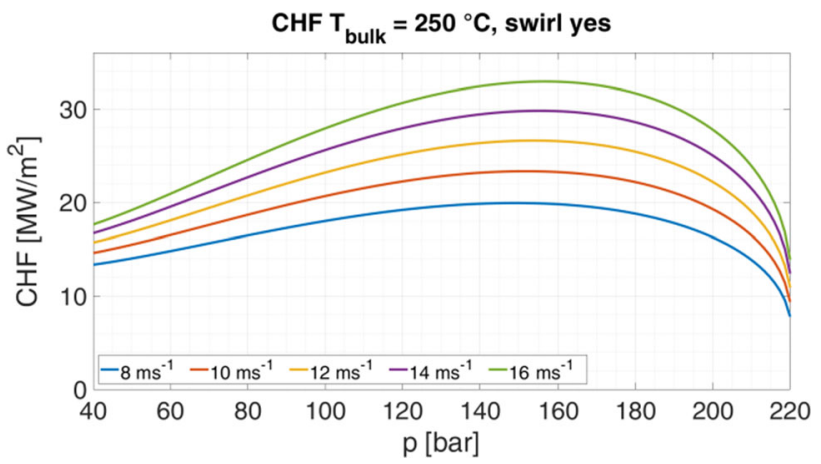

Fig. 3 Modified Tong-75 plots as a function of water pressure at $250{ }^{\circ} \mathrm{C}$, for different velocities. After $160 \mathrm{bar}, \mathrm{CHF}$ start to decrease 
It is important to highlight that the modified Tong-75 correlation was validated for lower temperature and pressure ranges ( $\mathrm{T}$ bulk of $115-180{ }^{\circ} \mathrm{C}$, pressure of 3.3-3.5 MPa), as reported in [21]. This means that the calculated values of CHF, on which the previous reflection is based, might be affected by uncertainty. In any case, the physical considerations and trends previously described do not lose their validity, and a deleterious effect on the CHF is always expected while approaching the water critical pressure. Only a dedicated experimental campaign would be able to support more extreme design choices (e.g. pressures above $15 \mathrm{MPa}$ ).

\section{Thermal analysis}

The geometry in Fig. 1 was meshed using 24608 PLANE77 elements. The FE analysis was carried out using ANSYS Workbench 18.2. A steady state analysis was performed with 3 different heat load conditions at the plasma facing surface of 5,10 and $20 \mathrm{MW} / \mathrm{m}^{2}$. Figure 4 shows that the proposed layout may operate without strong evaporation of $\mathrm{Sn}$ up to $20 \mathrm{MW} / \mathrm{m}^{2}$ for both the options.

Indeed, the maximum temperature of the plasma facing surface never exceeds $850{ }^{\circ} \mathrm{C}$ for $\mathrm{CuCrZr}$ and $930{ }^{\circ} \mathrm{C}$ for $\mathrm{W} / \mathrm{Cu}$. Moreover, $\mathrm{Sn}$ remains liquid always along the CPS outer surface already from $5 \mathrm{MW} / \mathrm{m}^{2}$ (see Fig. 5) ensuring the refilling of the Sn also at the minimum peak load assumed for the DEMO divertor in stationary conditions [16]. Where the power density deposited is lower than $5 \mathrm{MW} / \mathrm{m}^{2}$, Sn will be solid on the surface of the component, behaving like other metal plasma-facing materials. The PFC performance is not hindered in any way, because where the refill is needed (high load area) LM supply is ensured by the reservoir.

At $20 \mathrm{MW} / \mathrm{m}^{2}$ (Fig. 6 left) the $\mathrm{CuCrZr}$ heat sink may locally reach temperatures above the material limit suggested in [18]. However, the same happens in the monoblock design for the $\mathrm{CuCrZr}$ of the pipe, when exposed to the same heat load [1]. Therefore, this aspect it is not considered to be a showstopper. In any case, the copper

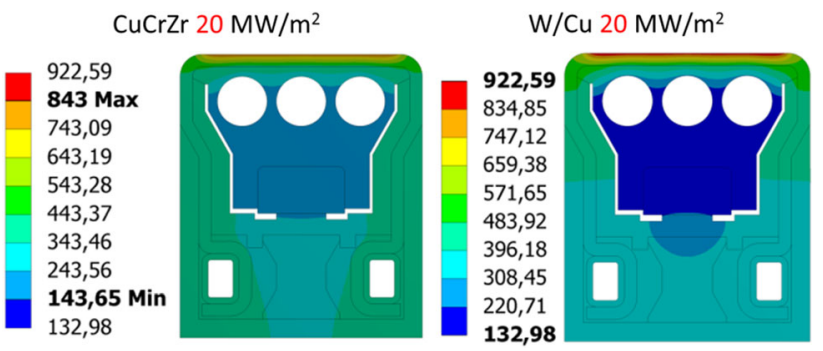

Fig. 4 Temperature field $\left({ }^{\circ} \mathrm{C}\right)$ with heat sink in $\mathrm{CuCrZr}$, on the left, and with heat sink in $\mathrm{W} / \mathrm{Cu}$ on the right

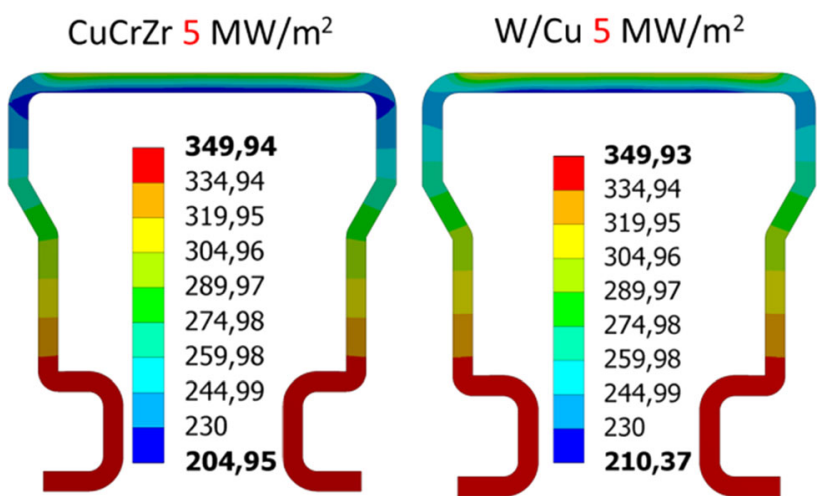

Fig. 5 . CPS temperatures $\left({ }^{\circ} \mathrm{C}\right)$ with heat sink in $\mathrm{CuCrZr}$, on the left, and with heat sink in $\mathrm{W} / \mathrm{Cu}$ on the right

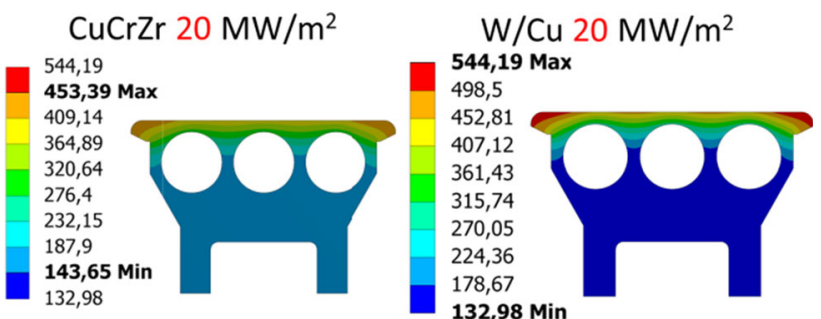

Fig. 6 Heat sink temperatures $\left({ }^{\circ} \mathrm{C}\right)$ in $\mathrm{CuCrZr}$ on the left, and in $\mathrm{W} / \mathrm{Cu}$ on the right

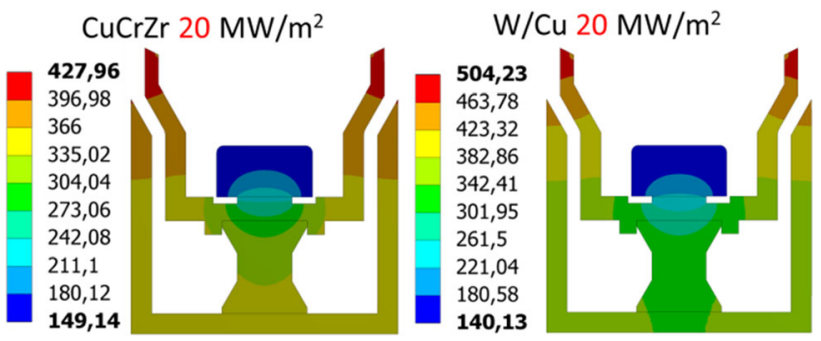

Fig. 7 EUROFER temperatures with heat sink in $\mathrm{CuCrZr}$, on the left, and with heat sink in $\mathrm{W} / \mathrm{Cu}$ on the right

content in the CuCrZr LMD is near 75\% larger than that of the monoblock. This means that the requirement 6 is not verified by this component. For this reason, the composite variant was considered. The results for the W/Cu option are reported in Fig. 6 right.

The maximum temperature at the heat sink, although increased, should not represent an issue for the composite material, as suggested in [12], but further studies are needed.

Finally, Fig. 7 shows that the maximum operating temperatures of the EUROFER parts that remain below $550{ }^{\circ} \mathrm{C}$ in both of the variants.

We observe that where the steel structure is in contact with the heat sink, the temperatures are lower than $300{ }^{\circ} \mathrm{C}$. 
However, as explained before, we plan to fix the parts by means of pins/slot joints, in order to allow differential thermal expansion between the different metals. In this way, it is reasonable to expect that the heat transfer among the parts is hindered, leading to an isolation effect of the steel and higher temperatures. In this simulation a perfect bonding was modelled, leaving more accurate considerations of the thermal contact conductance to future works.

\section{Conclusion}

In DEMO, power exhaust will represent one of the key challenges and advancements form the state-of-the-art ITER-like solution are currently under investigation. In the present work, an original, robust and feasible Sn-based liquid metal target layout for DEMO is proposed. 2D thermal analyses have confirmed performances that match those required by the DEMO monoblock design within the range of 5-20 MW $/ \mathrm{m}^{2}$. In particular, Sn can be kept always liquid and far from strong evaporative regimes. Operating limits potentially affecting the $\mathrm{CuCrZr}$ heat sink could be solved replacing it with a $\mathrm{W} / \mathrm{Cu}$ composite heat sink. With respect to the ITER-like solid solution, the CPS model proposed by ENEA ensures higher stability margin and complete compatibility with standard divertor design. The liquid tin refill pipe and a hot gas line should be easily integrated in the cassette due to the reduced dimension of the tubes Reflections regarding the CHF have been carried out, justifying our design choices, as well as underlining the potential criticalities of more extreme ones.

Towards the final design of a liquid divertor module some aspects are yet to be addressed. Above all, a 3D finite element model development is on-going to assess its thermo-mechanical response, including extremities and fixing solutions. CFD analysis is also needed for confirmation of 3D effect on the water flow. Moreover, electromagnetic forces arising during transients require additional studies on the structural stability and segmentation options. In addition to this, Sn corrosion and wettability are being investigated in ENEA. Corrosion resistant coatings produced using detonation gun or plasma spray are being tested to prevent the surfaces in contact with the liquid $\mathrm{Sn}$ from corrosion. Finally, a felt $2 \mathrm{~mm}$ thickness porous structure is the chosen CPS solution for the ENEA layout.

Acknowledgements This work has been carried out within the framework of the EUROfusion Consortium and has received funding from the Euratom research and training programme 2014-2018 and 2019-2020 under grant agreement No 633053. The views and opinions expressed herein do not necessarily reflect those of the European Commission.
Funding Open access funding provided by Ente per le Nuove Tecnologie, l'Energia e l'Ambiente within the CRUI-CARE Agreement.

Open Access This article is licensed under a Creative Commons Attribution 4.0 International License, which permits use, sharing, adaptation, distribution and reproduction in any medium or format, as long as you give appropriate credit to the original author(s) and the source, provide a link to the Creative Commons licence, and indicate if changes were made. The images or other third party material in this article are included in the article's Creative Commons licence, unless indicated otherwise in a credit line to the material. If material is not included in the article's Creative Commons licence and your intended use is not permitted by statutory regulation or exceeds the permitted use, you will need to obtain permission directly from the copyright holder. To view a copy of this licence, visit http://creativecommons. org/licenses/by/4.0/.

\section{References}

1. J.H. You et al., European divertor target concepts for DEMO: design rationales and high heat flux performance. J. Nucl. Mater. Energy 9, 171-117 (2018). https://doi.org/10.1016/j.nme.2018. 05.012

2. R.E. Nygren, F.L. Tabarés, Liquid surfaces for fusion plasma facing components - a critical review. Part I: physics and PSI. Nucl. Mater. Energy 9, 6-21 (2016). https://doi.org/10.1016/j. nme.2016.08.008

3. T. Morgan et al., Liquid metals as a divertor plasma-facing material explored using the Pilot-PSI and Magnum-PSI linear devices. Plasma Phys. Control. Fusion 60, 014025 (2018). https:// doi.org/10.1088/1361-6587/aa86cd

4. A. Cremona et al., Deuterium retention and erosion in liquid Sn samples exposed to D2 and Ar plasmas in GyM device. Nucl. Mater. Energy 17, 253-258 (2018). https://doi.org/10.1016/j.nme. 2018.11.010

5. W. Ou et al., Deuterium retention in Sn-filled samples exposed to fusion-relevant flux plasmas. Nucl. Fusion 60, 026008 (2020). https://doi.org/10.1088/1741-4326/ab5cd4

6. A. Manhard et al., Deuterium retention in solid and liquid tin after low-temperature plasma exposure. Nucl. Fusion 60, 106007 (2020).https://doi.org/10.1088/1741-4326/aba801

7. G. Mazzitelli et al., Experiments on the Frascati Tokamak Upgrade with a liquid tin limiter. Nucl. Fusion (2019). https://doi. org/10.1088/1741-4326/ab1d70

8. I.E. Lyublinski, A.V. Vertkov, Comparative assessment of application of low melting metals with capillary pore systems in a tokamak. Fusion Eng. Des. 89, 2953-2955 (2014). https://doi.org/ 10.1016/j.fusengdes.2014.09.015

9. A.Vertkov et al., Liquid tin limiter for FTU tokamak. Fusion Eng. Des. 117, 130-134 (2017). https://doi.org/10.1016/j.fusengdes. 2017.01.041

10. L.R. Kelman, W.D. Wilkinson, F.L. Yaggee, Resistance of materials to attack by liquid metals. Argonne National Laboratory, ANL-4417, 150, 1950, https://doi.org/10.2172/4419134

11. M. Hansen, K. Anderko, R. Elliott, Constitution of Binary Alloys, ser. McGraw-Hill series in materials science and engineering. McGraw-Hill, 1958. ' https://doi.org/10.1149/1.2428700

12. E. Tejado et al., The thermo-mechanical behaviour of $\mathrm{W}-\mathrm{Cu}$ metal matrix composites for fusion heat sink applications: The influence of the Cu content. J. Nucl. Mater. 498, 468-475 (2018). https://doi.org/10.1016/j.jnucmat.2017.08.020

13. A. von Muller et al., Melt infiltrated W-Cu composites as advanced heat sink materials for plasma facing components of 
future nuclear fusion devices. Fusion Eng. Des. 124, 455-459 (2017). https://doi.org/10.1016/j.fusengdes.2017.01.042

14. I.T.E.R. Organization, Historical Baseline Document: Appendix A, Materials Design Limit Data, Approved Version (2013)

15. K. Mergia et N. Bukos, Structural, thermal, electrical and magnetic propertiesof Eurofer 97 steel. J. Nucl. Mater. 373, 1-8 (2008). https://doi.org/10.1016/j.jnucmat.2007.03.267

16. R.P. Wenninger et al., DEMO divertor limitations during and in between ELMs. Nucl. Fusion 54, 114003 (2014). https://doi.org/ 10.1088/0029-5515/54/11/114003

17. F. Escourbiac et al., Assessment of critical heat flux margins on tungsten monoblocks of the ITER divertor vertical targets. Fusion Eng. Des. 146, 2036-2039 (2019). https://doi.org/10.1016/j. fusengdes.2019.03.094

18. D. Stork et al., Developing structural, high-heat-flux and plasma facing materials for near-term DEMO fusion power plant: the EU assessment. J. Nucl. Mater. 455, 277-291 (2014). https://doi.org/ 10.1016/j.jnucmat.2014.06.014
19. T.R. Barrett et al., Progress in the engineering design and assessment of the European DEMO first wall and divertor plasma facing components. Fusion Eng. Des. 109-111, 917-924 (2016). https://doi.org/10.1016/j.fusengdes.2016.01.052

20. S. Roccella et al., Ultrasonic test results before and after high heat flux testing on W-monoblock mock-ups of EU-DEMO vertical target, ISFNT 2019, submitted

21. E. Rabaglino et al., Prediction of heat transfer in water actively cooled plasma facing components, 2000, XVIII Congresso Nazionale sulla Trasmissione del Calore

22. A.R. Raffray et al. Critical heat flux analysis and R\&D for the design of the ITER divertor. J. Nucl. Mater. Energy 9, 171 - 17 (2016) . https://doi.org/10.1016/S0920-3796(99)00053-8

Publisher's Note Springer Nature remains neutral with regard to jurisdictional claims in published maps and institutional affiliations. 